\title{
Associations between Metabolic Syndrome and Obesity-Related Indices and Bone Mineral Density T-Score in Hemodialysis Patients
}

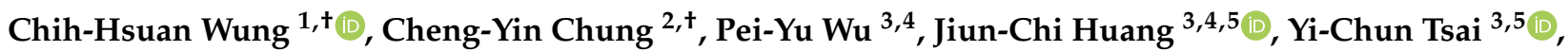 \\ Szu-Chia Chen ${ }^{3,4,5, *(\mathbb{D} \text {, Yi-Wen Chiu }}{ }^{3,5}$ and Jer-Ming Chang ${ }^{3,5}$
}

1 Department of Post Baccalaureate Medicine, Kaohsiung Medical University, Kaohsiung 807, Taiwan; knash031130@hotmail.com.tw

2 Division of Nephrology, Department of Internal Medicine, Ministry of Health and Welfare, Pingtung Hospital, Pingtung 900, Taiwan; capella913@gmail.com

3 Division of Nephrology, Department of Internal Medicine, Kaohsiung Medical University Hospital, Kaohsiung Medical University, Kaohsiung 807, Taiwan; wpuw17@gmail.com (P.-Y.W.); karajan77@gmail.com (J.-C.H.); lidam65@yahoo.com.tw (Y.-C.T.); chiuyiwen@gmail.com (Y.-W.C.); jemich@kmu.edu.tw (J.-M.C.)

4 Department of Internal Medicine, Kaohsiung Municipal Siaogang Hospital, Kaohsiung Medical University, 482, Shan-Ming Rd., Hsiao-Kang Dist., Kaohsiung 812, Taiwan

5 Faculty of Medicine, College of Medicine, Kaohsiung Medical University, Kaohsiung 807, Taiwan

* Correspondence: scarchenone@yahoo.com.tw; Tel.: +886-7-8036783-3440; Fax: +886-7-8063346

+ Both are equal contributors.

Citation: Wung, C.-H.; Chung, C.-Y.; Wu, P.-Y.; Huang, J.-C.; Tsai, Y.-C.; Chen, S.-C.; Chiu, Y.-W.; Chang, J.-M. Associations between Metabolic Syndrome and Obesity-Related Indices and Bone Mineral Density T-Score in Hemodialysis Patients. J. Pers. Med. 2021, 11, 775. https:// doi.org/10.3390/jpm11080775

Academic Editor: Jasminka Ilich-Ernst

Received: 5 July 2021

Accepted: 8 August 2021

Published: 9 August 2021

Publisher's Note: MDPI stays neutral with regard to jurisdictional claims in published maps and institutional affiliations.

Copyright: () 2021 by the authors. Licensee MDPI, Basel, Switzerland. This article is an open access article distributed under the terms and conditions of the Creative Commons Attribution (CC BY) license (https:// creativecommons.org/licenses/by/ $4.0 /)$.

\begin{abstract}
Previous studies have reported inconsistent results regarding the associations between metabolic syndrome (MetS) and obesity-related indices and bone mineral density (BMD). However, no previous studies have reported these associations among hemodialysis (HD) patients. The aims of this study were to investigate associations between MetS and its components and BMD T-score in HD patients and also between obesity-related indices and BMD T-score in HD patients with and without MetS. MetS was defined according to the Adult Treatment Panel III for Asians, and BMD T-score was calculated using dual-energy X-ray absorptiometry. Eight obesity-related indices were evaluated, including lipid accumulation product (LAP), visceral adiposity index (VAI), body adiposity index, conicity index (CI), body roundness index (BRI), abdominal volume index (AVI), waist-to-height ratio (WHtR), waist-hip ratio, and body mass index (BMI). One hundred and sixty-four patients undergoing HD were enrolled, and the prevalence of MetS was $61.6 \%$. MetS was significantly associated with high lumbar spine and total hip T-scores. Regarding the MetS components, abdominal obesity and low HDL-C were significantly associated with high lumbar spine, femoral neck, and total hip T-scores; hypertriglyceridemia was significantly associated with high lumbar spine and total hip T-scores; hyperglycemia was significantly associated with a high lumbar spine T-score, whereas high blood pressure was not associated with T-score at any site. In the patients with MetS, BMI, WHtR, AVI, and BRI were significantly associated with T-score at all sites, and high CI, VAI, and LAP were also related to a high lumbar T-score. However, these indices were not associated with T-score at any site in patients without MetS. This study demonstrated positive associations between MetS and its five components and BMD T-score among HD patients. MetS, abdominal obesity, hypertriglyceridemia, and low HDL-cholesterol were associated with low risk of osteoporosis among the HD patients. Furthermore, we found that some obesity-related indices were associated with BMD T-score among HD patients with MetS but not in those without MetS. Our study highlights the importance of BMI, WHtR, AVI, and BRI in predicting the risk of osteoporosis among HD patients with MetS. In clinical practice, they can be easily calculated through simple anthropometric measurements and routine laboratory examinations and be used to quickly and conveniently assess the risk of osteoporosis among HD patients.
\end{abstract}

Keywords: metabolic syndrome; MetS components; obesity-related index; bone mineral density 


\section{Introduction}

Osteoporosis is characterized by bone fragility caused by a loss of bone mass and deteriorating bone micro-architecture [1]. Hip and vertebral fractures are strongly associated with reductions in bone mineral density (BMD) of the hip and spine, respectively [2]. The risk factors associated with osteoporosis can be classified as being modifiable (such as malnutrition, cigarettes smoking, and alcohol consumption), non-modifiable (such as age, gender, and ethnicity), and secondary (such as the prolonged use of medications, diabetes mellitus, and chronic kidney disease (CKD)) [3]. Patients receiving dialysis are at a higher risk of osteoporosis and fractures than the general population [4], and the prevalence of osteoporosis in this population has been reported to range from $23 \%$ to $42 \%$ [5,6]. Moreover, osteoporosis-related fractures have been associated with a higher mortality rate in patients undergoing dialysis [7]. The pathophysiology of osteoporosis in patients with end-stage renal disease is multifactorial and complex, involving the aforementioned risk factors and CKD-related bone abnormalities [8].

Metabolic syndrome (MetS) is a group of conditions including abdominal obesity, high blood pressure, hyperglycemia, and dyslipidemia. According to the World Health Organization, the definition of obesity is having a body mass index (BMI) over 30 [9]. Individuals with predominant central obesity are prone to MetS. Each component of MetS affects bone metabolism [10]. However, previous studies have reported inconsistent and controversial relationships between components of MetS and osteoporosis [11]. With regard to the components of MetS, abdominal obesity has been shown to increase the mechanical load on the body and stimulate bone accrual [12]. Hypertension-induced abnormal calcium metabolism and interactions between bone marrow and hypertension have been reported $[11,13]$. Hyperglycemia has been shown to decrease bone turnover and induce osteocyte apoptosis [14], and dyslipidemia can uncouple bone remodeling leading to bone resorption [15,16]. With regard to the inconsistent findings in previous studies, abdominal obesity has both been associated with osteoporosis [17] and shown to have a protective effect against bone loss and consequently a lower risk of fractures [18]. Contradictory results have also been reported between dyslipidemia and osteoporosis [19,20]. In addition, regional discrepancies between BMD and MetS have been reported. Several studies have reported positive relationships between MetS and BMD in the United States and European countries [21-23], while other studies in Korea have shown a negative relationship [24,25]. Moreover, contradictory reports of the association between MetS and osteoporosis have also been reported in Taiwan [26,27]. Taken together, these findings indicate that multiple factors are associated with BMD and bone health [5].

Many studies have investigated the association between MetS and obesity-related indices among different populations [28-31]. However, no previous studies have investigated the relationship between obesity-related indices and BMD among hemodialysis (HD) patients with MetS. Therefore, the aims of this study were to investigate the associations between MetS and its components and BMD T-score in HD patients, and also between obesity-related indices and BMD T-score in HD patients with or without MetS.

\section{Subjects and Methods}

\subsection{Study Patients and Design}

A total of 178 patients who had attended the dialysis clinic at a hospital in southern Taiwan for more than 3 months and undergone maintenance HD thrice weekly for more than 3 months were included in June 2017. Each HD session lasted for 3.5-4.5 h, with a blood flow rate of $250-300 \mathrm{~mL} /$ minute and dialysate flow rate of $500 \mathrm{~mL} /$ minute. The exclusion criteria were as follows: (1) patients who did not wish to undergo dual-energy Xray absorptiometry (DXA) examinations $(n=6),(2)$ those with below-the-knee amputations of both legs $(n=3)$, and (3) those treated with antibiotics or hospitalized within 4 weeks before study entry $(n=5)$. Therefore, a total of 164 patients ( 74 females; 90 males; mean age $60.1 \pm 10.6$ years) were included. The Institutional Review Board of Kaohsiung Medical University Hospital approved this study (KMUH-IRB-F(I)-20150074), and all of the patients 
provided written informed consent before enrollment. The methods were performed following relevant guidelines.

\subsection{BMD and Body Composition Measurements}

Body composition was assessed using a Horizon Wi DXA system (Hologic, Waltham, MA, USA). BMD was assessed at three sites: total hip, femoral neck, and lumbar spine (L2-L4). To minimize variations in measurements, one radiologic technologist performed all scans and calculations. T-scores were used for comparisons.

\subsection{Collection of Demographic, Medical, and Laboratory Data}

Demographic (age and sex) and medical history (diabetes and hypertension) information was obtained from the patients' medical records. Twelve-hour fasting blood samples were also obtained within 1 month of enrollment and analyzed using a COBAS Integra 400 system (Roche Diagnostics GmbH, D-68298 Mannheim, Germany).

\subsection{Definition of MetS}

The National Cholesterol Education Program Adult Treatment Panel (NCEP-ATP) III guidelines [32] and modified criteria for Asians [33] were used to define MetS as three or more of the following five criteria: (1) abdominal obesity (waist circumference (WC) $>80 \mathrm{~cm}$ in females or $>90 \mathrm{~cm}$ in males); (2) hyperglycemia (a previous diagnosis of diabetes or fasting whole-blood glucose concentration $\geq 110 \mathrm{mg} / \mathrm{dL}$ ); (3) high blood pressure (a diagnosis of hypertension, receiving treatment for hypertension, systolic blood pressure $\geq 130 \mathrm{mmHg}$, or diastolic blood pressure $\geq 85 \mathrm{mmHg}$ ); (4) low concentration of high-density lipoprotein cholesterol (HDL-C) $(<50 \mathrm{mg} / \mathrm{dL}$ in females or $<40 \mathrm{mg} / \mathrm{dL}$ in males); and (5) hypertriglyceridemia (triglyceride (TG) concentration $\geq 150 \mathrm{mg} / \mathrm{dL}$ ).

\subsection{Calculations of Obesity-Related Indices}

The following obesity-related indices were calculated.

$\mathrm{BMI}=$ body weight $(\mathrm{BW})(\mathrm{kg}) /$ body height $(\mathrm{BH})^{2}(\mathrm{~m})$.

Waist-hip ratio $($ WHR $)=W C(\mathrm{~cm}) /$ hip circumference $(\mathrm{HC})(\mathrm{cm})$.

Waist-to-height ratio $(\mathrm{WHtR})=\mathrm{WC}(\mathrm{cm}) /$ height $(\mathrm{cm})$.

Abdominal volume index $(\mathrm{AVI})=\frac{2 \times\left(\mathrm{WC}_{(\mathrm{cm})}\right)^{2}+0.7 \times\left(\mathrm{WC}_{(\mathrm{cm})}-\mathrm{HC}(\mathrm{cm})\right)^{2}}{1000}[34]$.

Body roundness index $(\mathrm{BRI})=364.2-365.5 \times \sqrt{1-\left(\frac{\mathrm{WC}_{(\mathrm{m})}}{0.5 \times \mathrm{RH}_{(\mathrm{m})}}\right)^{2}}$ [35].

Conicity index $(\mathrm{CI})=\frac{\mathrm{WC}_{(\mathrm{m})}}{0.109 \times \sqrt{\frac{\mathrm{BW}_{(\mathrm{kg})}^{\mathrm{BH}(\mathrm{m})}}{2}}}[36]$.

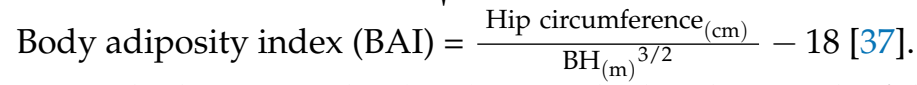

Visceral adiposity index (VAI) was calculated using the following sex-specific equations:

$\mathrm{VAI}=\left(\frac{\mathrm{WC}_{(\mathrm{cm})}}{39.68+(1.88 \times \mathrm{BMI})}\right) \times\left(\frac{\mathrm{TG}_{(\mathrm{mmol} / \mathrm{L})}}{1.03}\right) \times\left(\frac{1.31}{\mathrm{HDL}_{(\mathrm{mmol} / \mathrm{L})}}\right)$ in males, and

$\mathrm{VAI}=\left(\frac{\mathrm{WC}_{(\mathrm{cm})}}{36.58+(1.89 \times \mathrm{BMI})}\right) \times\left(\frac{\mathrm{TG}_{(\mathrm{mmol} / \mathrm{L})}}{0.81}\right) \times\left(\frac{1.52}{\mathrm{HDL}_{(\mathrm{mmol} / \mathrm{L})}}\right)$ in females [38].

Lipid accumulation product (LAP) was also calculated using the following sex-specific equations:

$$
\begin{aligned}
& \mathrm{LAP}=\left(\mathrm{WC}_{(\mathrm{cm})}-65\right) \times \mathrm{TG}_{(\mathrm{mmol} / \mathrm{L})} \text { in males, and } \\
& \mathrm{LAP}=\left(\mathrm{WC}_{(\mathrm{cm})}-58\right) \times \mathrm{TG}_{(\mathrm{mmol} / \mathrm{L})} \text { in females [39]. }
\end{aligned}
$$

\subsection{Statistical Analysis}

Descriptive statistics are presented as mean \pm standard deviation, percentage, or median (25th-75th percentile) for TG, HD duration, and parathyroid hormone (PTH). The chi-square test was used to examine differences between groups for categorical variables, 
and the independent $t$ test was used for continuous variables. Associations between MetS and obesity-related indices and BMD T-score were examined using multivariable linear regression analysis. A $p$ value $<0.05$ was considered to be statistically significant. All statistical analyses were performed using SPSS software for Windows version 20.0 (SPSS Inc. Chicago, IL, USA). The two sample means statement (POWER Procedure using SAS version 9.4, SAS Institute, Cary, NC, USA) performs a power test involving the difference between two independent means.

\section{Results}

A total of 164 patients were enrolled (54.9\% men and $45.1 \%$ women) with a mean age of $60.1 \pm 10.6$ years. The prevalence of MetS was $61.6 \%$.

\subsection{Comparisons of the Baseline Characteristics of the HD Patients with and without MetS}

Table 1 shows comparisons of the characteristics of the patients with and without MetS. Compared to the patients without MetS, those with MetS tended to be older and to have higher rates of diabetes and hypertension and a lower duration of HD, In addition, the patients with MetS had a lower HDL-C level and higher BW, WC, HC, lumbar spine T-score, total hip T-score, fasting glucose, and TG. Moreover, the measured obesity-related indices (BMI, WHR, WHtR, AVI, BRI, CI, BAI, VAI, and LAP) were all higher in the patients with MetS.

We calculated a sample size of 63 for the MetS (-) group and 101 for MetS (+) with lumbar spine T-score, femoral neck T-score, or total hip T-score between the two groups having a mean difference of 1.05 (standard deviation (SD) 1.60, 1.63), 0.30 (SD 0.95, 1.28), or 0.53 (SD 1.00, 1.38), respectively, which provided $99 \%, 42 \%$, or $82 \%$ power to detect such a difference with a two-sample $t$ test with a two-sided type I error of 0.05 .

Table 1. Comparison of baseline characteristics among chronic HD patients stratified by MetS status.

\begin{tabular}{|c|c|c|c|c|}
\hline Characteristics & $\begin{array}{l}\text { All Patients } \\
\quad(n=164)\end{array}$ & $\begin{array}{c}\text { MetS }(-) \\
(n=63)\end{array}$ & $\begin{array}{l}\text { MetS (+) } \\
(n=101)\end{array}$ & $p$ \\
\hline Age (years) & $60.1 \pm 10.6$ & $58.9 \pm 11.2$ & $60.9 \pm 10.2$ & 0.236 \\
\hline Men (\%) & 54.9 & 52.4 & 56.4 & 0.612 \\
\hline Diabetes (\%) & 51.8 & 23.8 & 69.3 & $<0.001$ \\
\hline Hypertension (\%) & 92.7 & 82.5 & 99.0 & $<0.001$ \\
\hline Duration of HD (years) & $6.9(3.3-13.1)$ & $10.5(6.0-16.6)$ & $4.8(2.5-9.6)$ & $<0.001$ \\
\hline Body height (cm) & $161.6 \pm 8.2$ & $160.9 \pm 8.3$ & $162.0 \pm 8.1$ & 0.385 \\
\hline Body weight (kg) & $62.6 \pm 12.0$ & $56.0 \pm 9.7$ & $66.8 \pm 11.6$ & $<0.001$ \\
\hline Waist circumference $(\mathrm{cm})$ & $87.2 \pm 10.9$ & $79.3 \pm 10.0$ & $92.0 \pm 8.3$ & $<0.001$ \\
\hline Hip circumference (cm) & $92.8 \pm 7.6$ & $89.2 \pm 6.5$ & $95.0 \pm 7.5$ & $<0.001$ \\
\hline \multicolumn{5}{|l|}{ DXA Parameters } \\
\hline Lumbar spine T-score & $-1.21 \pm 1.69$ & $-1.89 \pm 1.60$ & $-0.84 \pm 1.63$ & $<0.001$ \\
\hline Femoral neck T-score & $-2.29 \pm 1.18$ & $-2.48 \pm 0.95$ & $-2.18 \pm 1.28$ & 0.139 \\
\hline Total hip T-score & $-1.79 \pm 1.28$ & $-2.13 \pm 1.00$ & $-1.60 \pm 1.38$ & 0.009 \\
\hline \multicolumn{5}{|l|}{ Laboratory parameters } \\
\hline Fasting glucose (mg/dL) & $111.4 \pm 43.3$ & $90.8 \pm 21.1$ & $124.3 \pm 48.4$ & $<0.001$ \\
\hline Albumin $(\mathrm{g} / \mathrm{dL})$ & $3.9 \pm 0.3$ & $3.9 \pm 0.2$ & $3.9 \pm 0.3$ & 0.091 \\
\hline Hemoglobin (g/dL) & $10.3 \pm 1.3$ & $10.3 \pm 1.5$ & $10.4 \pm 1.4$ & 0.689 \\
\hline Triglycerides (mg/dL) & $111(82.3-164.8)$ & $81(66-102)$ & $146(104.5-205)$ & $<0.001$ \\
\hline Total cholesterol (mg/dL) & $172.2 \pm 42.6$ & $168.8 \pm 35.1$ & $174.3 \pm 46.7$ & 0.423 \\
\hline HDL-cholesterol (mg/dL) & $44.0 \pm 12.9$ & $53.6 \pm 13.2$ & $38.0 \pm 8.4$ & $<0.001$ \\
\hline LDL-cholesterol (mg/dL) & $89.4 \pm 29.6$ & $84.4 \pm 27.1$ & $92.6 \pm 30.8$ & 0.086 \\
\hline CaXP product $\left(\mathrm{mg}^{2} / \mathrm{dL}^{2}\right)$ & $41.4 \pm 10.1$ & $41.3 \pm 9.7$ & $41.4 \pm 10.4$ & 0.921 \\
\hline $\mathrm{PTH}(\mathrm{pg} / \mathrm{mL})$ & $301.1(159.4-507.7)$ & $284.6(158.4-506.4)$ & $319.2(159.7-513.1)$ & 0.362 \\
\hline \multicolumn{5}{|l|}{ MetS component } \\
\hline Abdominal obesity (\%) & 54.9 & 19.0 & 77.2 & $<0.001$ \\
\hline Hypertriglyceridemia (\%) & 32.9 & 6.3 & 49.5 & $<0.001$ \\
\hline Low HDL-cholesterol (\%) & 57.9 & 22.2 & 80.2 & $<0.001$ \\
\hline
\end{tabular}


Table 1. Cont.

\begin{tabular}{|c|c|c|c|c|}
\hline Characteristics & $\begin{array}{l}\text { All Patients } \\
\quad(n=164)\end{array}$ & $\begin{array}{c}\text { MetS }(-) \\
(n=63)\end{array}$ & $\begin{array}{l}\text { MetS (+) } \\
(n=101)\end{array}$ & $p$ \\
\hline Hyperglycemia (\%) & 61.0 & 30.2 & 80.2 & $<0.001$ \\
\hline High blood pressure (\%) & 92.7 & 82.5 & 99.0 & $<0.001$ \\
\hline \multicolumn{5}{|l|}{ Obesity-related indices } \\
\hline $\operatorname{BMI}\left(\mathrm{kg} / \mathrm{m}^{2}\right)$ & $23.9 \pm 4.0$ & $21.6 \pm 3.1$ & $25.4 \pm 3.8$ & $<0.001$ \\
\hline WHR & $0.94 \pm 0.08$ & $0.89 \pm 0.07$ & $0.97 \pm 0.06$ & $<0.001$ \\
\hline WHtR & $0.54 \pm 0.07$ & $0.49 \pm 0.06$ & $0.57 \pm 0.05$ & $<0.001$ \\
\hline AVI & $15.5 \pm 3.8$ & $12.8 \pm 3.2$ & $17.1 \pm 3.1$ & $<0.001$ \\
\hline BRI & $4.2 \pm 1.4$ & $3.3 \pm 1.2$ & $4.8 \pm 1.2$ & $<0.001$ \\
\hline $\mathrm{CI}$ & $1.29 \pm 0.09$ & $1.23 \pm 0.09$ & $1.32 \pm 0.07$ & $<0.001$ \\
\hline BAI & $27.4 \pm 4.6$ & $26.0 \pm 4.1$ & $28.2 \pm 4.7$ & 0.002 \\
\hline VAI & $6.4 \pm 7.1$ & $2.9 \pm 2.2$ & $8.4 \pm 8.2$ & $<0.001$ \\
\hline LAP & $46.6 \pm 53.0$ & $19.0 \pm 14.9$ & $63.2 \pm 60.3$ & $<0.001$ \\
\hline
\end{tabular}

Abbreviations: HD, hemodialysis; MetS, metabolic syndrome; DXA, dual-energy X-ray absorptiometry; BMD, bone mineral density; HDL; high-density lipoprotein; LDL, low-density lipoprotein; CaXP product, calcium $\times$ phosphorus product; PTH, parathyroid hormone; BMI, body mass index; WHR, waist-hip ratio; WHtR, waist-to-height ratio; AVI, abdominal volume index; BRI, body roundness index; CI, conicity index; BAI, body adiposity index; VAI, visceral adiposity index; LAP, lipid accumulation product.

\subsection{Associations between MetS and Its Components and T-Score in All Study Patients}

Associations between MetS and its components and T-score in all of the study patients ( $n=164)$ using multivariable linear regression analysis after adjusting for age, gender, log HD duration, albumin, hemoglobin, total cholesterol, low-density lipoprotein cholesterol (LDL-C), CaXP product, and log PTH are shown in Table 2. MetS was significantly associated with a high lumbar spine T-score (unstandardized coefficient $(\beta), 1.116 ; p<0.001$ ) and total hip T-score $(\beta, 0.503 ; p=0.021)$, but femoral neck T-score was not. For the MetS components, hyperglycemia $(\beta, 0.782 ; p=0.006)$, hypertriglyceridemia $(\beta, 0.674 ; p=0.026)$, low HDL-C $(\beta, 0.838 ; p=0.002)$, and abdominal obesity $(\beta, 1.091 ; p<0.001)$ were significantly associated with a high lumbar spine T-score, but high blood pressure was not. In addition, abdominal obesity $(\beta, 0.679 ; p=0.001)$ and low HDL-C $(\beta, 0.537 ; p=0.003)$ were significantly associated with a high femoral neck T-score, but hypertriglyceridemia, hyperglycemia and high blood pressure were not. Moreover, low HDL-C $(\beta, 0.658 ; p=0.001)$, hypertriglyceridemia $(\beta, 0.502 ; p=0.026)$, and abdominal obesity $(\beta, 0.678 ; p=0.002)$ were significantly associated with total hip T-score, but hyperglycemia and high blood pressure were not.

Table 2. Association between MetS and its components and BMD T-score using multivariable linear regression analysis in all study patients $(n=164)$.

\begin{tabular}{|c|c|c|c|c|c|c|}
\hline \multirow{2}{*}{ Parameters } & \multicolumn{2}{|c|}{ Lumbar Spine T-Score } & \multicolumn{2}{|c|}{ Femoral Neck T-Score } & \multicolumn{2}{|l|}{ Total Hip T-Score } \\
\hline & Coefficient $\beta(95 \%$ CI) & $p$ & Coefficient $\beta(95 \%$ CI $)$ & $p$ & Coefficient $\beta(95 \%$ CI) & $p$ \\
\hline MetS & $1.116(0.543,1.689)$ & $<0.001$ & $0.374(-0.018,0.766)$ & 0.061 & $0.503(0.076,0.931)$ & 0.021 \\
\hline MetS component & & & & & & \\
\hline Abdominal obesity & $1.091(0.514,1.668)$ & $<0.001$ & $0.679(0.299,1.058)$ & 0.001 & $0.678(0.258,1.099)$ & 0.002 \\
\hline Hypertriglyceridemia & $0.674(0.083,1.264)$ & 0.026 & $0.314(-0.092,0.719)$ & 0.128 & $0.502(0.061,0.942)$ & 0.026 \\
\hline Low HDL-cholesterol & $0.838(0.313,1.363)$ & 0.002 & $0.537(0.184,0.890)$ & 0.003 & $0.658(0.274,1.043)$ & 0.001 \\
\hline Hyperglycemia & $0.782(0.225,1.339)$ & 0.006 & $0.020(-0.363,0.402)$ & 0.918 & $0.172(-0.247,0.591)$ & 0.418 \\
\hline High blood pressure & $0.203(-0.907,1.314)$ & 0.718 & $-0.593(-1.342,0.156)$ & 0.119 & $-0.456(-1.281,0.370)$ & 0.277 \\
\hline
\end{tabular}

Values expressed as unstandardized coefficient $\beta$ and $95 \%$ confidence interval (CI). Abbreviations are the same as in Table 1. Adjusted for age, gender, log HD duration, albumin, hemoglobin, total cholesterol, LDL-cholesterol, CaXP product, and log PTH.

\subsection{Associations between Obesity-Related Indices and T-Score in the Patients with MetS}

Associations between obesity-related indices and T-score using multivariable linear regression analysis in the patients with MetS $(n=101)$ are shown in Table 3. The following 
multivariable linear regression analyses were performed for different indices as shown below:

1. Adjusted for age, sex, diabetes, hypertension, log HD duration, fasting glucose, albumin, hemoglobin, log TG, total cholesterol, HDL-C, LDL-C, CaXP product, and $\log$ PTH for BMI, WHR, WHtR, AVI, BRI, CI, and BAI.

2. Adjusted for age, sex, diabetes, hypertension, log HD duration, fasting glucose, albumin, hemoglobin, total cholesterol, LDL-C, CaXP product, and log PTH for VAI.

3. Adjusted for age, sex, diabetes, hypertension, log HD duration, fasting glucose, albumin, hemoglobin, total cholesterol, HDL-C, LDL-C, CaXP product, and log PTH for LAP.

Table 3. Association between obesity-related indices and BMD T-score using multivariable linear regression analysis in patients with MetS $(n=101)$.

\begin{tabular}{|c|c|c|c|c|c|c|}
\hline \multirow{2}{*}{$\begin{array}{l}\text { Obesity-Related } \\
\text { Indices }\end{array}$} & \multicolumn{2}{|c|}{ Lumbar Spine T-Score } & \multicolumn{2}{|c|}{ Femoral Neck T-Score } & \multicolumn{2}{|c|}{ Total Hip T-Score } \\
\hline & Coefficient $\beta$ (95\% CI) & $p$ & Coefficient $\beta(95 \%$ CI $)$ & $p$ & Coefficient $\beta$ (95\% CI) & $p$ \\
\hline $\mathrm{BMI}\left(\right.$ per $\left.1 \mathrm{~kg} / \mathrm{m}^{2}\right) *$ & $0.120(0.029,0.211)$ & 0.010 & $0.109(0.041,0.177)$ & 0.002 & $0.105(0.029,0.181)$ & 0.007 \\
\hline WHR (per 0.1) * & $0.419(-0.131,0.968)$ & 0.133 & $0.335(-0.075,0.745)$ & 0.108 & $0.323(-0.128,0.773)$ & 0.158 \\
\hline WHtR (per 0.1) * & $0.929(0.304,1.555)$ & 0.004 & $0.605(0.128,1.082)$ & 0.014 & $0.561(0.034,1.089)$ & 0.037 \\
\hline $\mathrm{AVI}(\text { per } 1)^{*}$ & $0.192(0.087,0.297)$ & 0.001 & $0.138(0.058,0.219)$ & 0.001 & $0.119(0.028,0.209)$ & 0.011 \\
\hline BRI (per 1)* & $0.411(0.129,0.692)$ & 0.005 & $0.267(0.052,0.481)$ & 0.016 & $0.245(0.008,0.483)$ & 0.043 \\
\hline $\mathrm{CI}($ per 0.1$) *$ & $0.557(0.034,1.080)$ & 0.037 & $0.215(-0.184,0.613)$ & 0.287 & $0.168(-0.269,0.606)$ & 0.445 \\
\hline $\mathrm{BAI}($ per 1$) *$ & $0.063(-0.017,0.143)$ & 0.121 & $0.030(-0.029,0.090)$ & 0.314 & $0.030(-0.036,0.095)$ & 0.367 \\
\hline $\mathrm{VAI}($ per 1$)+$ & $0.090(0.019,0.161)$ & 0.013 & $0.019(-0.034,0.072)$ & 0.485 & $0.031(-0.027,0.088)$ & 0.291 \\
\hline LAP (per 10) \# & $0.148(0.020,0.277)$ & 0.024 & $0.057(-0.043,0.158)$ & 0.257 & $0.081(-0.028,0.191)$ & 0.142 \\
\hline
\end{tabular}

Values expressed as unstandardized coefficient $\beta$ and $95 \%$ confidence interval (CI). Abbreviations are the same as in Table $1 .{ }^{*}$ Adjusted for age, gender, diabetes, hypertension, log HD duration, fasting glucose, albumin, hemoglobin, log triglyceride, total cholesterol, HDLcholesterol, LDL-cholesterol, CaXP product, and log PTH. † Adjusted for age, gender, diabetes, hypertension, log HD duration, fasting glucose, albumin, hemoglobin, total cholesterol, LDL-cholesterol, CaXP product, and log PTH. \# Adjusted for age, gender, diabetes, hypertension, log HD duration, fasting glucose, albumin, hemoglobin, total cholesterol, HDL-cholesterol, LDL-cholesterol, CaXP product, and $\log$ PTH.

After multivariable linear regression analysis, high values of AVI (per $1 ; \beta, 0.192$; $p=0.001$ ), WHtR (per 0.1; $\beta, 0.929 ; p=0.004)$, BMI (per $\left.1 \mathrm{~kg} / \mathrm{m}^{2} ; \beta, 0.120 ; p=0.010\right)$, VAI (per $1 ; \beta, 0.090 ; p=0.013)$, CI (per 0.1; $\beta, 0.557 ; p=0.037$ ), BRI (per $1 ; \beta, 0.411 ; p=0.005$ ), and LAP (per 10; $\beta, 0.148 ; p=0.024$ ) were significantly associated with a high lumbar spine T-score, but WHR and BAI were not. In addition, high values of BRI (per $1 ; \beta, 0.267$; $p=0.016$ ), WHtR (per 0.1; $\beta, 0.605 ; p=0.014$ ), BMI (per $1 \mathrm{~kg} / \mathrm{m}^{2} ; \beta, 0.109 ; p=0.002$ ), and AVI (per $1 ; \beta, 0.138 ; p=0.001$ ) were significantly associated with a high femoral neck T-score, but WHR, CI, BAI, VAI, and LAP were not. Regarding total hip T-score, high values of AVI (per $1 ; \beta, 0.119 ; p=0.011)$, WHtR (per $0.1 ; \beta, 0.561 ; p=0.037)$, BMI (per $1 \mathrm{~kg} / \mathrm{m}^{2} ; \beta$, $0.105 ; p=0.007$ ), and BRI (per $1 ; \beta, 0.245 ; p=0.043$ ) were significantly associated with a high total hip T-score, but WHR, CI, BAI, VAI, and LAP were not.

\subsection{Associations between Obesity-Related Indices and T-Score in the Patients without MetS}

Association between obesity-related indices and T-score using multivariable linear regression analysis in the patients without MetS $(n=63)$ are shown in Table 4 . There were no significant correlations between any of the indices and T-score at any site. 
Table 4. Association between obesity-related indices and BMD T-score using multivariable linear regression analysis in patients without MetS $(n=63)$.

\begin{tabular}{|c|c|c|c|c|c|c|}
\hline \multirow{2}{*}{$\begin{array}{l}\text { Obesity-Related } \\
\text { Indices }\end{array}$} & \multicolumn{2}{|c|}{ Lumbar Spine T-Score } & \multicolumn{2}{|c|}{ Femoral Neck T-Score } & \multicolumn{2}{|c|}{ Total Hip T-Score } \\
\hline & Coefficient $\beta$ (95\% CI) & $p$ & Coefficient $\beta$ (95\% CI) & $p$ & Coefficient $\beta$ (95\% CI) & $p$ \\
\hline $\mathrm{BMI}\left(\right.$ per $\left.1 \mathrm{~kg} / \mathrm{m}^{2}\right) *$ & $0.041(-0.131,0.213)$ & 0.631 & $0.059(-0.031,0.149)$ & 0.194 & $0.051(-0.047,0.148)$ & 0.299 \\
\hline WHR (per 0.1) * & $0.226(-0.626,1.077)$ & 0.592 & $0.410(-0.060,0.879)$ & 0.085 & $0.321(-0.173,0.814)$ & 0.195 \\
\hline WHtR (per 0.1) * & $-0.032(-0.944,0.879)$ & 0.943 & $0.134(-0.377,0.646)$ & 0.597 & $0.089(-0.447,0.625)$ & 0.738 \\
\hline $\mathrm{AVI}(\text { per } 1)^{*}$ & $0.084(-0.082,0.250)$ & 0.312 & $0.083(-0.010,0.175)$ & 0.078 & $0.066(-0.031,0.163)$ & 0.177 \\
\hline BRI (per 1)* & $-0.036(-0.505,0.432)$ & 0.876 & $0.059(-0.205,0.323)$ & 0.652 & $0.035(-0.241,0.312)$ & 0.797 \\
\hline $\mathrm{CI}($ per 0.1$) *$ & $0.215(-0.447,0.876)$ & 0.513 & $0.115(-0.274,0.504)$ & 0.553 & $0.061(-0.347,0.469)$ & 0.764 \\
\hline $\mathrm{BAI}(\operatorname{per} 1) *$ & $-0.155(-0.321,0.011)$ & 0.066 & $-0.065(-0.150,0.021)$ & 0.136 & $-0.052(-0.142,0.037)$ & 0.243 \\
\hline $\mathrm{VAI}($ per 1$)+$ & $0.056(-0.195,0.308)$ & 0.651 & $-0.044(-0.183,0.095)$ & 0.525 & $-0.036(-0.181,0.110)$ & 0.620 \\
\hline LAP (per 10) \# & $0.184(-0.213,0.582)$ & 0.352 & $0.046(-0.185,0.277)$ & 0.687 & $0.003(-0.239,0.246)$ & 0.977 \\
\hline
\end{tabular}

Values expressed as unstandardized coefficient $\beta$ and $95 \%$ confidence interval (CI). Abbreviations are the same as in Table 1. ${ }^{*}$ Adjusted for age, gender, diabetes, hypertension, log HD duration, fasting glucose, albumin, hemoglobin, log triglyceride, total cholesterol, HDLcholesterol, LDL-cholesterol, CaXP product, and log PTH. + Adjusted for age, gender, diabetes, hypertension, log HD duration, fasting glucose, albumin, hemoglobin, total cholesterol, LDL-cholesterol, CaXP product, and log PTH. \# Adjusted for age, gender, diabetes, hypertension, log HD duration, fasting glucose, albumin, hemoglobin, total cholesterol, HDL-cholesterol, LDL-cholesterol, CaXP product, and $\log$ PTH.

\section{Discussion}

In this study, we found positive correlations between MetS and its components and BMD T-score, except for high blood pressure. In addition, in the patients with MetS, high BMI, WHtR, AVI, and BRI were associated with high lumbar spine, femoral neck, and total hip T-scores. Moreover, high CI, VAI, and LAP were also correlated with a high lumbar T-score. However, none of the studied obesity-related indices were associated with T-score at any site in the patients without MetS.

The first important finding of this study is the positive association between MetS and BMD T-score in the HD patients. MetS affects the regulation of hormones, mechanical loading of the body, and biochemical profile, all of which affect bone health. Many studies have suggested that MetS is associated with BMD through mechanical loading and adiposity [40]. Visceral adipose tissue resulting in central obesity can produce adipokines and affect bone health. Leptin is a peptide hormone secreted by adipocytes, and it can control food intake via leptin receptors in the hypothalamus [41]. Individuals with hyperleptinemia consume more food and gain weight, leading to increased mechanical load [42]. Vaspin is a novel adipokine secreted by visceral adipose tissue, which can induce bone formation by protecting osteoblasts from apoptosis, and it has been shown to suppress bone erosion through osteoclast inhibition [43]. Omentin-1 is a novel visceral adipose-tissue-derived adipokine that can block the inflammatory responses and impair the anti-osteoblastic and pro-osteoclastic effects of activated macrophages [44]. Taken together, these findings suggest that MetS and obesity increase BMD through both mechanical load and adipokine regulation.

We also analyzed each component of MetS and the associations with T-score, and found that abdominal obesity, hypertriglyceridemia, low HDL-C, and hyperglycemia were associated with T-score, whereas high blood pressure was not. Patients undergoing chronic dialysis have a lower BMD than healthy subjects of similar age due to CKD-related mineral and bone disorders [45]. Abdominal obesity can reflect higher mechanical loading on the bone, which then stimulates bone accrual [12]. Many studies have reported a positive relationship between TG level and BMD [46-48]. TG levels are associated with abdominal fat mass, which is also related to abdominal obesity [49]. The association between low HDL-C and high BMD is consistent with the study by Jiang et al.; however the mechanism underlying this association is unclear due to complex genetic and molecular factors [50]. However, we did not find an association between high blood pressure and T-score. Calcium abnormalities are a key factor linking hypertension and osteoporosis. Hypertension is related to high sodium intake, which causes an increase in urinary calcium excretion and, 
subsequently, a decrease in calcium blood level. This in turn can result in the upregulation of the PTH level, leading to bone turnover [11,51]. In contrast to our study, Hanley et al. reported an association between hypertension and higher BMD in both genders [52]. In addition, in a study conducted by Tseng et al., there was no significant association between BMD and systolic blood pressure in either sex, and a strong inverse relationship was found between bone mineral loss and diastolic blood pressure in both sexes [53]. Moreover, in a study of women and men with hypertension, Yang et al. found lower femoral neck BMD in the women and higher femoral neck BMD in the men [54]. Further large population studies are needed to evaluate the relationship between hypertension and BMD.

The second important finding of this study is that high BMI, WHtR, AVI, and BRI were associated with high lumbar spine, femoral neck, and total hip T-scores in the patients with MetS. We also found associations between high CI, VAI, and LAP and a high lumbar T-score. Dogan et al. also reported an association between a high BMI and high BMD, consistent with our findings [55]. Several studies have reported that a high BW can lead to bone remodeling to compensate for mechanical load [56,57]. Other studies have reported associations between BMI and leptin level, leading to the production and activation of osteoblasts [58,59]. In addition, high WHtR was associated with high T-score in our study. WHtR is based on WC and reflects central obesity [60]. Abdominal obesity may increase BMD by stimulating bone growth and increasing the bones' weight bearing capacity [61]. AVI and BRI are used to assess obesity and are associated with impaired glucose tolerance, and they have been reported to be good indicators of MetS status [34,62]. Overweight and obesity increase mechanical load. Taken together, these findings may explain the association between BMD and hyperglycemia and MetS. High CI, VAI, and LAP were also associated with a high lumbar T-score in the present study. CI reflects central obesity and has also been reported to be a good indicator of MetS status [63]. VAI is a surrogate of visceral fat accumulation, and it can also be used to assess central obesity [64]. LAP can be used to assess visceral fat and TG levels, and it has been shown to reflect the risk of MetS and cardiovascular disease [65]. The possible explanation for the associations between $\mathrm{CI}, \mathrm{VAI}$, and LAP with BMD may be related to central obesity and function of the lumbar spine, which is to bear the upper part of the body. Central obesity increases the mass of the upper body leading to direct mechanical load on the lumbar spine. This can then lead to an increase in bone remodeling and elevated BMD.

Another important finding of this study is that there was no association between any of the obesity-related indices and BMD T-score among the HD patients without MetS. In our study patients, the duration of HD was longer in those without MetS than in those with MetS. Long-term dialysis can worsen inflammation-mediated proteolysis, hypermetabolism, and nutrient loss, and these factors can lead to malnutrition [66]. Weight loss is often an obvious sign of malnutrition [67], which is inconsistent with the characteristics of MetS. Another possible explanation may be the small number of patients in this group. Therefore, malnutrition and small patient number may partially explain the non-significant association between the obesity-related indices and BMD in the patients without MetS.

There are several limitations to this study. First, we enrolled the study patients from a single regional hospital in southern Taiwan, and therefore, our findings may not be generalizable to other areas. Second, due to the cross-sectional design of the study, we could not assess causal relationships and long-term clinical outcomes. Further longitudinal studies are needed to verify our findings. Third, all of the participants in our study were Taiwanese, and therefore our conclusions may not be generalizable to other ethnicities. Nonetheless, our results highlight the importance of MetS and obesity-related indices on osteoporosis in HD patients. Finally, the overall number of patients in this study was low, future large-scale research are needed.

In conclusion, we identified associations between MetS and its five components and obesity-related indices and BMD T-score among HD patients. MetS, abdominal obesity, hypertriglyceridemia, and low HDL-cholesterol were associated with low risk of osteoporosis among the HD patients. We also found that some obesity-related indices were 
associated with BMD T-score among the HD patients with MetS, but not in those without MetS. Our study highlights the importance of BMI, WHtR, AVI, and BRI in predicting the risk of osteoporosis among the HD patients with MetS. In clinical practice, they can be easily calculated through simple anthropometric measurements and routine laboratory examinations and be used to quickly and conveniently assess the risk of osteoporosis among HD patients.

Author Contributions: Conceptualization, C.-H.W., C.-Y.C., P.-Y.W., J.-C.H., Y.-C.T., S.-C.C., Y.W.C. and J.-M.C.; methodology, C.-H.W., C.-Y.C., P.-Y.W., J.-C.H., Y.-C.T. and S.-C.C.; software, S.-C.C.; validation, S.-C.C.; formal analysis, C.-H.W. and S.-C.C.; investigation, C.-H.W., C.-Y.C., P.-Y.W., J.-C.H., Y.-C.T., S.-C.C., Y.-W.C. and J.-M.C.; writing-original draft preparation, C.-H., C.Y.C. and S.-C.C.; writing-review and editing, S.-C.C.; supervision, S.-C.C., Y.-W.C. and J.-M.C.; project administration, S.-C.C.; funding acquisition, S.-C.C. All authors have read and agreed to the published version of the manuscript.

Funding: This research received no external funding.

Institutional Review Board Statement: The study was conducted according to the guidelines of the Declaration of Helsinki, and ap-proved by the Institutional Review Board of Kaohsiung Medical University Chung-Ho Memorial Hospital (KMUHIRB-F(I)-20150074 and 2015/10/16 approval.

Informed Consent Statement: Informed consent was obtained from all subjects involved in the study.

Data Availability Statement: Data may be available upon request to interested researchers. Please send data requests to: Szu-Chia Chen, PhD, MD. Division of Nephrology, Department of Internal Medicine, Kaohsiung Medical University Hospital, Kaohsiung Medical University.

Conflicts of Interest: We have no financial interest in the information contained in the manuscript.

\section{References}

1. Sugimoto, T.; Sato, M.; Dehle, F.C.; Brnabic, A.J.; Weston, A.; Burge, R. Lifestyle-Related Metabolic Disorders, Osteoporosis, and Fracture Risk in Asia: A Systematic Review. Value Health Reg. Issues 2016, 9, 49-56. [CrossRef]

2. Compston, J.E.; McClung, M.R.; Leslie, W.D. Osteoporosis. Lancet 2019, 393, 364-376. [CrossRef]

3. Pouresmaeili, F.; Kamalidehghan, B.; Kamarehei, M.; Goh, Y.M. A comprehensive overview on osteoporosis and its risk factors. Ther. Clin. Risk Manag. 2018, 14, 2029-2049. [CrossRef]

4. Nickolas, T.L.; Leonard, M.B.; Shane, E. Chronic kidney disease and bone fracture: A growing concern. Kidney Int. 2008, 74, 721-731. [CrossRef]

5. Slouma, M.; Sahli, H.; Bahlous, A.; Laadhar, L.; Smaoui, W.; Rekik, S.; Gharsallah, I.; Sallami, M.; Moussa, F.B.; Elleuch, M.; et al. Mineral bone disorder and osteoporosis in hemodialysis patients. Adv. Rheumatol. 2020, 60, 15. [CrossRef] [PubMed]

6. Khan, M.I.; Syed, G.M.; Khan, A.I.; Sirwal, I.A.; Anwar, S.K.; Al-Oufi, A.R.; Balbaid, K.A. Mean bone mineral density and frequency of occurrence of osteopenia and osteoporosis in patients on hemodialysis: A single-center study. Saudi J. Kidney Dis. Transplant. 2014, 25, 38-43. [CrossRef]

7. Moe, S.M. Renal Osteodystrophy or Kidney-Induced Osteoporosis? Curr. Osteoporos. Rep. 2017, 15, 194-197. [CrossRef]

8. Evenepoel, P.; Cunningham, J.; Ferrari, S.; Haarhaus, M.; Javaid, M.K.; Lafage-Proust, M.H.; Prieto-Alhambra, D.; Torres, P.U.; Cannata-Andia, J.; European Renal Osteodystrophy workgroup aiotCKDMBDwgotERAE; et al. European Consensus Statement on the diagnosis and management of osteoporosis in chronic kidney disease stages G4-G5D. Nephrol. Dial. Transplant. 2021, 36, 42-59. [CrossRef]

9. Hwang, L.C.; Bai, C.H.; Chen, C.J. Prevalence of obesity and metabolic syndrome in Taiwan. J. Formos. Med. Assoc. 2006, 105, 626-635. [CrossRef]

10. Grundy, S.M. Metabolic syndrome update. Trends Cardiovasc. Med. 2016, 26, 364-373. [CrossRef]

11. Wong, S.K.; Chin, K.Y.; Suhaimi, F.H.; Ahmad, F.; Ima-Nirwana, S. The Relationship between Metabolic Syndrome and Osteoporosis: A Review. Nutrients 2016, 8, 347. [CrossRef]

12. Chin, K.Y.; Chan, C.Y.; Subramaniam, S.; Muhammad, N.; Fairus, A.; Ng, P.Y.; Jamil, N.A.; Aziz, N.A.; Ima-Nirwana, S.; Mohamed, N. Positive association between metabolic syndrome and bone mineral density among Malaysians. Int. J. Med. Sci. 2020, 17, 2585-2593. [CrossRef] [PubMed]

13. Do Carmo, L.; Harrison, D.G. Hypertension and osteoporosis: Common pathophysiological mechanisms. Med. Nov. Technol. Devices 2020, 8, 100047. [CrossRef] 
14. Tanaka, K.; Yamaguchi, T.; Kanazawa, I.; Sugimoto, T. Effects of high glucose and advanced glycation end products on the expressions of sclerostin and RANKL as well as apoptosis in osteocyte-like MLO-Y4-A2 cells. Biochem. Biophys. Res. Commun. 2015, 461, 193-199. [CrossRef]

15. Dawodu, D.; Patecki, M.; Dumler, I.; Haller, H.; Kiyan, Y. oxLDL inhibits differentiation of mesenchymal stem cells into osteoblasts via the CD36 mediated suppression of Wnt signaling pathway. Mol. Biol. Rep. 2019, 46, 3487-3496. [CrossRef]

16. Frommer, K.W.; Hasseli, R.; Schaffler, A.; Lange, U.; Rehart, S.; Steinmeyer, J.; Rickert, M.; Sarter, K.; Zaiss, M.M.; Culmsee, C.; et al. Free Fatty Acids in Bone Pathophysiology of Rheumatic Diseases. Front. Immunol. 2019, 10, 2757. [CrossRef] [PubMed]

17. Jankowska, E.A.; Rogucka, E.; Medras, M. Are general obesity and visceral adiposity in men linked to reduced bone mineral content resulting from normal ageing? A population-based study. Andrologia 2001, 33, 384-389. [CrossRef]

18. De Laet, C.; Kanis, J.A.; Oden, A.; Johanson, H.; Johnell, O.; Delmas, P.; Eisman, J.A.; Kroger, H.; Fujiwara, S.; Garnero, P.; et al. Body mass index as a predictor of fracture risk: A meta-analysis. Osteoporos. Int. 2005, 16, 1330-1338. [CrossRef]

19. Adami, S.; Braga, V.; Zamboni, M.; Gatti, D.; Rossini, M.; Bakri, J.; Battaglia, E. Relationship between lipids and bone mass in 2 cohorts of healthy women and men. Calcif. Tissue Int. 2004, 74, 136-142. [CrossRef]

20. Yamaguchi, T.; Sugimoto, T.; Yano, S.; Yamauchi, M.; Sowa, H.; Chen, Q.; Chihara, K. Plasma lipids and osteoporosis in postmenopausal women. Endocr. J. 2002, 49, 211-217. [CrossRef] [PubMed]

21. Hernandez, J.L.; Olmos, J.M.; Pariente, E.; Martinez, J.; Valero, C.; Garcia-Velasco, P.; Nan, D.; Llorca, J.; Gonzalez-Macias, J. Metabolic syndrome and bone metabolism: The Camargo Cohort study. Menopause 2010, 17, 955-961. [CrossRef]

22. Kinjo, M.; Setoguchi, S.; Solomon, D.H. Bone mineral density in adults with the metabolic syndrome: Analysis in a populationbased U.S. sample. J. Clin. Endocrinol. Metab. 2007, 92, 4161-4164. [CrossRef]

23. von Muhlen, D.; Safii, S.; Jassal, S.K.; Svartberg, J.; Barrett-Connor, E. Associations between the metabolic syndrome and bone health in older men and women: The Rancho Bernardo Study. Osteoporos. Int. 2007, 18, 1337-1344. [CrossRef] [PubMed]

24. Kim, H.; Oh, H.J.; Choi, H.; Choi, W.H.; Lim, S.K.; Kim, J.G. The association between bone mineral density and metabolic syndrome: A Korean population-based study. J. Bone Miner. Metab. 2013, 31, 571-578. [CrossRef] [PubMed]

25. Kim, T.; Park, S.; Pak, Y.S.; Lee, S.; Lee, E.H. Association between metabolic syndrome and bone mineral density in Korea: The Fourth Korea National Health and Nutrition Examination Survey (KNHANES IV), 2008. J. Bone Miner. Metab. 2013, 31, 652-662. [CrossRef]

26. Lin, H.H.; Huang, C.Y.; Hwang, L.C. Association between metabolic syndrome and osteoporosis in Taiwanese middle-aged and elderly participants. Arch. Osteoporos. 2018, 13, 48. [CrossRef]

27. Loke, S.S.; Chang, H.W.; Li, W.C. Association between metabolic syndrome and bone mineral density in a Taiwanese elderly population. J. Bone Miner. Metab. 2018, 36, 200-208. [CrossRef]

28. Wu, Y.; Li, H.; Tao, X.; Fan, Y.; Gao, Q.; Yang, J. Optimised anthropometric indices as predictive screening tools for metabolic syndrome in adults: A cross-sectional study. BMJ Open 2021, 11, e043952. [CrossRef]

29. Adejumo, E.N.; Adejumo, A.O.; Azenabor, A.; Ekun, A.O.; Enitan, S.S.; Adebola, O.K.; Ogundahunsi, O.A. Anthropometric parameter that best predict metabolic syndrome in South west Nigeria. Diabetes Metab. Syndr. 2019, 13, 48-54. [CrossRef]

30. Lin, I.T.; Lee, M.Y.; Wang, C.W.; Wu, D.W.; Chen, S.C. Gender Differences in the Relationships among Metabolic Syndrome and Various Obesity-Related Indices with Nonalcoholic Fatty Liver Disease in a Taiwanese Population. Int. J. Environ. Res. Public Health 2021, 18, 857.

31. Guo, X.; Ding, Q.; Liang, M. Evaluation of Eight Anthropometric Indices for Identification of Metabolic Syndrome in Adults with Diabetes. Diabetes Metab. Syndr. Obes. 2021, 14, 1431-1443. [CrossRef]

32. Isomaa, B.; Henricsson, M.; Almgren, P.; Tuomi, T.; Taskinen, M.R.; Groop, L. The metabolic syndrome influences the risk of chronic complications in patients with type II diabetes. Diabetologia 2001, 44, 1148-1154. [CrossRef] [PubMed]

33. Tan, C.E.; Ma, S.; Wai, D.; Chew, S.K.; Tai, E.S. Can we apply the National Cholesterol Education Program Adult Treatment Panel definition of the metabolic syndrome to Asians? Diabetes Care 2004, 27, 1182-1186. [CrossRef] [PubMed]

34. Guerrero-Romero, F.; Rodríguez-Morán, M. Abdominal volume index. An anthropometry-based index for estimation of obesity is strongly related to impaired glucose tolerance and type 2 diabetes mellitus. Arch. Med. Res. 2003, 34, 428-432. [CrossRef]

35. Thomas, D.M.; Bredlau, C.; Bosy-Westphal, A.; Mueller, M.; Shen, W.; Gallagher, D.; Maeda, Y.; McDougall, A.; Peterson, C.M.; Ravussin, E.; et al. Relationships between body roundness with body fat and visceral adipose tissue emerging from a new geometrical model. Obesity 2013, 21, 2264-2271. [CrossRef]

36. Valdez, R. A simple model-based index of abdominal adiposity. J. Clin. Epidemiol. 1991, 44, 955-956. [CrossRef]

37. Bergman, R.N.; Stefanovski, D.; Buchanan, T.A.; Sumner, A.E.; Reynolds, J.C.; Sebring, N.G.; Xiang, A.H.; Watanabe, R.M. A better index of body adiposity. Obesity 2011, 19, 1083-1089. [CrossRef]

38. Amato, M.C.; Giordano, C.; Galia, M.; Criscimanna, A.; Vitabile, S.; Midiri, M.; Galluzzo, A.; for the AlkaMeSy Study Group. Visceral Adiposity Index: A reliable indicator of visceral fat function associated with cardiometabolic risk. Diabetes Care 2010, 33, 920-922. [CrossRef] [PubMed]

39. Kahn, H.S. The "lipid accumulation product" performs better than the body mass index for recognizing cardiovascular risk: A population-based comparison. BMC Cardiovasc. Disord. 2005, 5, 26. [CrossRef] [PubMed] 
40. Chin, K.Y.; Wong, S.K.; Ekeuku, S.O.; Pang, K.L. Relationship Between Metabolic Syndrome and Bone Health-An Evaluation of Epidemiological Studies and Mechanisms Involved. Diabetes Metab. Syndr. Obes. 2020, 13, 3667-3690. [CrossRef]

41. Vu, J.P.; Larauche, M.; Flores, M.; Luong, L.; Norris, J.; Oh, S.; Liang, L.J.; Waschek, J.; Pisegna, J.R.; Germano, P.M. Regulation of Appetite, Body Composition, and Metabolic Hormones by Vasoactive Intestinal Polypeptide (VIP). J. Mol. Neurosci. 2015, 56, 377-387. [CrossRef]

42. Farkhondeh, T.; Llorens, S.; Pourbagher-Shahri, A.M.; Ashrafizadeh, M.; Talebi, M.; Shakibaei, M.; Samarghandian, S. An Overview of the Role of Adipokines in Cardiometabolic Diseases. Molecules 2020, 25, 5218. [CrossRef] [PubMed]

43. Weiner, J.; Zieger, K.; Pippel, J.; Heiker, J.T. Molecular Mechanisms of Vaspin Action-From Adipose Tissue to Skin and Bone, from Blood Vessels to the Brain. Adv. Exp. Med. Biol. 2019, 1111, 159-188. [PubMed]

44. Rao, S.S.; Hu, Y.; Xie, P.L.; Cao, J.; Wang, Z.X.; Liu, J.H.; Yin, H.; Huang, J.; Tan, Y.J.; Luo, J.; et al. Omentin-1 prevents inflammation-induced osteoporosis by downregulating the pro-inflammatory cytokines. Bone Res. 2018, 6, 9. [CrossRef] [PubMed]

45. Nakanishi, K.; Shishido, K.; Kumata, C.; Ito, K.; Nakashima, Y.; Wakasa, M. Bone density of the femoral neck in patients on maintenance dialysis. PLoS ONE 2018, 13, e0197965. [CrossRef] [PubMed]

46. Son, J.-S.; Koh, H.-M.; Park, J.-K. Relationship between Triglyceride and Bone Mineral Density in Healthy Korean Men. Korean J. Health Promot. 2015, 15, 115. [CrossRef]

47. Mirzababaei, A.; Mirzaei, K.; Khorrami-Nezhad, L.; Maghbooli, Z.; Keshavarz, S.A. Metabolically healthy/unhealthy components may modify bone mineral density in obese people. Arch. Osteoporos. 2017, 12, 95. [CrossRef] [PubMed]

48. Hirasawa, A.; Makita, K.; Akahane, T.; Yamagami, W.; Makabe, T.; Yokota, M.; Horiba, Y.; Ogawa, M.; Yanamoto, S.; Deshimaru, R.; et al. Osteoporosis is less frequent in endometrial cancer survivors with hypertriglyceridemia. Jpn. J. Clin. Oncol. 2015, 45, 127-131. [CrossRef]

49. Chi, J.H.; Shin, M.S.; Lee, B.J. Identification of hypertriglyceridemia based on bone density, body fat mass, and anthropometry in a Korean population. BMC Cardiovasc. Disord. 2019, 19, 66. [CrossRef]

50. Jiang, J.; Qiu, P.; Wang, Y.; Zhao, C.; Fan, S.; Lin, X. Association between serum high-density lipoprotein cholesterol and bone health in the general population: A large and multicenter study. Arch. Osteoporos. 2019, 14, 36. [CrossRef]

51. Ilic, K.; Obradovic, N.; Vujasinovic-Stupar, N. The relationship among hypertension, antihypertensive medications, and osteoporosis: A narrative review. Calcif. Tissue Int. 2013, 92, 217-227. [CrossRef]

52. Hanley, D.A.; Brown, J.P.; Tenenhouse, A.; Olszynski, W.P.; Ioannidis, G.; Berger, C.; Prior, J.C.; Pickard, L.; Murray, T.M.; Anastassiades, T.; et al. Associations among disease conditions, bone mineral density, and prevalent vertebral deformities in men and women 50 years of age and older: Cross-sectional results from the Canadian Multicentre Osteoporosis Study. J. Bone Miner. Res. 2003, 18, 784-790. [CrossRef] [PubMed]

53. Tseng, Y.H.; Huang, K.C.; Liu, M.L.; Shu, W.T.; Sheu, W.H. Association between metabolic syndrome (MS) and bone mineral loss: A cross-sectional study in Puli Township in Taiwan. Arch. Gerontol. Geriatr. 2009, 49 (Suppl. 2), S37-S40. [CrossRef]

54. Yang, S.; Nguyen, N.D.; Center, J.R.; Eisman, J.A.; Nguyen, T.V. Association between hypertension and fragility fracture: A longitudinal study. Osteoporos. Int. 2014, 25, 97-103. [CrossRef] [PubMed]

55. Dogan, A.; Nakipoglu-Yuzer, G.F.; Yildizgoren, M.T.; Ozgirgin, N. Is age or the body mass index (BMI) more determinant of the bone mineral density (BMD) in geriatric women and men? Arch. Gerontol. Geriatr. 2010, 51, 338-341. [CrossRef]

56. Kang, D.; Liu, Z.; Wang, Y.; Zhang, H.; Feng, X.; Cao, W.; Wang, P. Relationship of body composition with bone mineral density in northern Chinese men by body mass index levels. J. Endocrinol. Investig. 2014, 37, 359-367. [CrossRef] [PubMed]

57. Kumar, A.; Sharma, A.K.; Mittal, S.; Kumar, G. The Relationship Between Body Mass Index and Bone Mineral Density in Premenopausal and Postmenopausal North Indian Women. J. Obstet. Gynaecol. India 2016, 66, 52-56. [CrossRef]

58. Reid, I.R.; Baldock, P.A.; Cornish, J. Effects of Leptin on the Skeleton. Endocr. Rev. 2018, 39, 938-959. [CrossRef] [PubMed]

59. Hamrick, M.W.; Della-Fera, M.A.; Choi, Y.H.; Pennington, C.; Hartzell, D.; Baile, C.A. Leptin treatment induces loss of bone marrow adipocytes and increases bone formation in leptin-deficient ob/ob mice. J. Bone Miner. Res. 2005, 20, 994-1001. [CrossRef] [PubMed]

60. Chiu, T.H.; Huang, Y.C.; Chiu, H.; Wu, P.Y.; Chiou, H.C.; Huang, J.C.; Chen, S.C. Comparison of Various Obesity-Related Indices for Identification of Metabolic Syndrome: A Population-Based Study from Taiwan Biobank. Diagnostics 2020, 10, 1081. [CrossRef]

61. Deng, G.; Yin, L.; Li, K.; Hu, B.; Cheng, X.; Wang, L.; Zhang, Y.; Xu, L.; Xu, S.; Zhu, L.; et al. Relationships between anthropometric adiposity indexes and bone mineral density in a cross-sectional Chinese study. Spine J. 2021, 21, 332-342. [CrossRef]

62. Liu, B.; Liu, B.; Wu, G.; Yin, F. Relationship between body-roundness index and metabolic syndrome in type 2 diabetes. Diabetes Metab. Syndr. Obes. 2019, 12, 931-935. [CrossRef]

63. Mantzoros, C.S.; Evagelopoulou, K.; Georgiadis, E.I.; Katsilambros, N. Conicity index as a predictor of blood pressure levels, insulin and triglyceride concentrations of healthy premenopausal women. Horm. Metab. Res. 1996, 28, 32-34. [CrossRef] [PubMed]

64. Xiao, H.; Xiong, C.; Shao, X.; Gao, P.; Chen, H.; Ning, J.; Chen, Y.; Zou, Z.; Hong, G.; Li, X.; et al. Visceral Adiposity Index and Chronic Kidney Disease in a Non-Diabetic Population: A Cross-Sectional Study. Diabetes Metab. Syndr. Obes. 2020, 13, 257-265. [CrossRef] [PubMed] 
65. Adu, E.A.; Obirikorang, C.; Acheampong, E.; Kwakye, A.S.; Fokuoh, F.; Obirikorang, Y.; Anto, E.O.; Batu, E.N.; Amoah, B.Y.; Ansong, P.N.; et al. Lipid accumulation product (LAP) index as a potential risk assessment for cardiovascular risk stratification among type II diabetes mellitus in a Ghanaian population: A cross-sectional study. Cogent Med. 2019, 6, 1639880. [CrossRef]

66. Bramania, P.; Ruggajo, P.; Bramania, R.; Mahmoud, M.; Furia, F. Nutritional Status of Patients on Maintenance Hemodialysis at Muhimbili National Hospital in Dar es Salaam, Tanzania: A Cross-Sectional Study. J. Nutr. Metab. 2021, 2021, 6672185. [CrossRef]

67. Saunders, J.; Smith, T. Malnutrition: Causes and consequences. Clin. Med. 2010, 10, 624-627. [CrossRef] 